\title{
Association of Helicobacter Pylori Infection with Portal Hypertensive Gastropathy in Liver Cirrhosis
}

\author{
AFAF T. EL-NASHAR, M.D.*; HASSAN A. HASSANIEN, M.D.**; ASHRAF A. ASKER, M.D.** and \\ HANAA M. ABD EL-AZEEM, M.Sc.**
}

The Departments of Pathology* and General Medicine**, Faculty of Medicine, Sohag University

\begin{abstract}
Background: Portal hypertensive gastropathy (PHG) is an important cause of morbidity in patients with Liver cirrhosis (LC). Helicobacter pylori (HP) infection is a common cause of gastritis and is an endemic disease in Egypt.
\end{abstract}

Aim of the Work: To study the presence of H. pylori infection in cases of LC with and without PHG.

Material and Methods: Fifty patients with LC including 25 cases with PHG and 25 cases without PHG who attended Sohag Faculty Hospital during the period 9/2016-3/2017 were examined for the presence of $\mathrm{H}$ pylori infection histologically using Hematoxyline and Eosin and Geimsa stains. The correlation between $\mathrm{H}$ pylori infection and the severity of PHG was studied statistically.

Results: H. pylori were detected in $76 \%$ of cases of LC ( $72 \%$ in LC with PHG and $80 \%$ of cases LC without PHG). Although there was an association between $\mathrm{H}$ pylori infection and the severity of PHG (5/7 cases), there was no statistically significant difference between $\mathrm{H}$ pylori infection and $\mathrm{PHG}$.

Conclusion: H. pylori infection can be seen in cases of LC irrespective of the presence or absence of PHG more than in general population.

Key Words: H. pylori - PHG - Liver cirrhosis - Geimsa stain.

\section{Introduction}

PORTAL hypertensive gastropathy (PHG) is the term used to describe the endoscopic appearance of gastric mucosa, with a characteristic mosaiclike pattern with or without red spots, seen in patients with cirrhotic or non-cirrhotic portal hypertension. The mosaic pattern appears as white reticular network separating areas of raised red or pink mucosa resembling the skin of a snake. PHG is seen mainly in the body and the fundus of the

Correspondence to: Dr. Afaf T. El-Nashar, The Department of Pathology Medicine, Faculty of Medicine, Sohag University stomach. When PHG is severe, it can include discrete cherry red spots, fine pink speckling, collectively called red marks. In fact, Portal hypertensive gastropathy (PHG) is an important cause of bleeding in patients with cirrhosis associated with portal hypertension. The characteristic histological finding of PHG is dilated capillaries and venules in the mucosa and submucosa without erosion, inflammation, or fibrinous [1]

The reported prevalence of PHG varies greatly. In a study of 373 cirrhotic patients, 299 (80.2\%) had PHG [2] . In the HALT-C trial (Hepatitis C Antiviral Long Term Treatment against hepatitis C), 374 (37\%) of 1011 patients with biopsy-proven cirrhosis or bridging fibrosis from hepatitis $\mathrm{C}$ had PHG [3].

The overall prevalence of $\mathrm{PHG}$ varies from $51 \%$ to $98 \%$. The wide variation in the reported prevalence is perhaps related to patient selection, absence of uniform criteria and classification, and more importantly, the differences in inter- and intraobserver variation $[4]$.

Hemodynamic changes in patients with portal hypertension lead to hyperdynamic congestion with a change in gastric mucosal blood flow that leads to activation of cytokines, growth factors, and hormones [5]. This hyperdynamic circulation impairs gastric mucosal defense mechanisms, causes release of proinflammatory mediators, and inhibits growth factors which render gastric mucosa more susceptible to injury and impair mucosal healing [6]. This vulnerable mucosa becomes predisposed to bleeding and the decreased gastric mucosal perfusion may explain the increased rate of erosions, ulcers, and bleeding in PHG [7] Abnormal regulation of the gastric microcirculation 
in PHG may render gastric mucosa more vulnerable to hypoxia, and more susceptible to noxious factors. Tumor necrosis factor alpha (TNF- $\alpha$ ) may directly contribute to the hyperdynamic circulation in PHG. Patients and animal models with portal hypertension had an elevated TNF- $\alpha$ level which stimulated release of nitric oxide (NO) and prostacyclin, important mediators of a hyperdynamic circulation [8].

Numerous molecular and cellular mechanisms have been investigated regarding the pathogenesis of PHG; P53-upregulated modulator of apoptosis (PUMA) was markedly induced in gastric mucosa in patients or mouse models of PHG [9].

$\mathrm{H}$ pylori infection continues to be a major public health issue worldwide. In 2015, approximately 4.4 billion individuals worldwide were estimated to be positive for $\mathrm{H}$ pylori [10]

H. pylori infection is closely related to peptic ulcer, chronic gastritis, and gastric cancer; but the relationship between $\mathrm{H}$. pylori infection and $\mathrm{PHG}$ is not clear.

\section{Aim of the work:}

To determine the presence of $\mathrm{H}$. pylori infection in cirrhotic patients with/without PHG and to find out an association between $\mathrm{H}$. pylori infection and the severity of PHG.

\section{Patients and Methods}

This is a case control observational study. It included 50 patients with liver cirrhosis (LC) divided into 25 cases of LC with PHG and 25 cases of LC without PHG. Those patients attended Sohag University General Medicine department during the period from $9 / 2016$ to $3 / 2017$. The age range of the patients was 28-68 y and all patients agreed to share in this study with a written consent and the study was given an approval of the Scientific and Ethical Committee of Sohag, Faculty of Medicine. Exclusion criteria from the study were as followed: Patients with primary or metastatic hepatic malignancy, patients with gastric surgery or peptic ulcer, recent acute gastric or variceal bleeding, and patients with prior antibiotic medical therapy.

Investigations for the patients in the study: 1liver function tests including serum bilirubin, serum albumen and prothrombin time. 2- Abdominal Sonography. 3- Upper endoscopy with gastric punch biopsy for histopathological detection of $\mathrm{H}$. pylori using H\&E and Geimsa staining. The severity of liver cirrhosis was assessed using Child-Pugh classification [11]. The severity of PHG was assessed using McCormack classification [1] .

Table (1): Child-Pugh scoring system of severity of liver cirrhosis.

\begin{tabular}{llll}
\hline & \multicolumn{1}{c}{1} & \multicolumn{1}{c}{2} & \multicolumn{1}{c}{3} \\
\hline Encephalopathy & None & Grade 1-2 & Grade 3-4 \\
Ascitis & None & Mild/moderate & Sever \\
Bilirubin $(\mathrm{mg} / \mathrm{dl})$ & $<2$ & $2-3$ & $>3$ \\
Albumin $(\mathrm{g} / \mathrm{dl})$ & $>3.5$ & $2.8-3.5$ & $<2.8$ \\
Prothrombin time & $>4$ & $4-6$ & $<6$ \\
\hline
\end{tabular}

$\mathrm{A}=5-6$ points. $\quad \mathrm{B}=7-9$ points. $\quad \mathrm{C}=10-15$ points.

Table (2): McCormack classification of the severity of PHG.

\begin{tabular}{ll}
\hline Mild & Fine pink speckling \\
& Superficial reddening \\
& Mosaic pattern \\
& Discrete red spots \\
Sever & Diffuse hemorrhagic lesion \\
\hline
\end{tabular}

\section{Results}

In the present study 50 cases of LC divided into 25 cases of LC with PHG ( 2 cases of HBV, 18 cases $\mathrm{HCV}, 1$ case of $\mathrm{HCV}+\mathrm{HBV}$, and 4 cases free from viruses) and 25 cases of $\mathrm{LC}$ without $\mathrm{PHG}$ (2 cases HBV, 19 cases HCV, 1 case HBV+HCV and 3 cases free from viruses) (Table 3 ). Those cases included 24 females (14 cases LC+PHG and 10 cases LC without PHG) and 26 males (11 cases LC+PHG and 15 cases LC without PHG). The age range of the involved cases was 28-72 years with median 55 and mean \pm SD 54.84 \pm 11.06 . H pylori infection was detected in 18 cases of $\mathrm{LC}+\mathrm{PHG}$ with 5/7 sever PHG and in 20 cases of LC without PHG (Table 3, graph 1 and Fig. 1). There was no statistically significant difference between the presence of $\mathrm{H}$. pylori infection in PHG patients and control group $(p=0.51)$. The $\mathrm{H}$. pylori infection was statistically similar in patients with severe PHG (5/7 cases) and mild PHG (13/18 cases $(p=0.7)$. There was no statistically significant correlation between $\mathrm{H}$ pylori infection and the clinical variants as age of the patients, duration of the cirrhosis, type of viral hepatitis and the severity of cirrhosis. 
Table (3): Main clinical and histopathological findings of the studied cases.

\begin{tabular}{llll}
\hline & $\begin{array}{c}\text { Liver cirrhosis } \\
\text { with PHG(25) }\end{array}$ & $\begin{array}{c}\text { Liver cirrhosis } \\
\text { without PHG(25) }\end{array}$ & Total \\
\hline Male & 11 & 15 & 26 \\
Female & 14 & 10 & 24 \\
Child-Pugh: & & & \\
A & 4 & 6 & 10 \\
B & 14 & 9 & 23 \\
C & 7 & 10 & 17 \\
HBV & 2 & 2 & 4 \\
HCV & $18(72 \%)$ & $19(76 \%)$ & 37 \\
HCV+HBV & 1 & 1 & 2 \\
Free viruses & 4 & 3 & 7 \\
Ascitis & 16 & 1 & 17 \\
PHG: & & & \\
Mild & 18 & - & \\
Sever & 7 & - & \\
H. Pylori: & & & \\
$\quad$ +ve & 13 & 20 & $12(24 \%)$ \\
-ve & $518 / 25(72 \%)$ & $20 / 25(80 \%)$ & \\
& 5 & 5 & \\
\hline
\end{tabular}

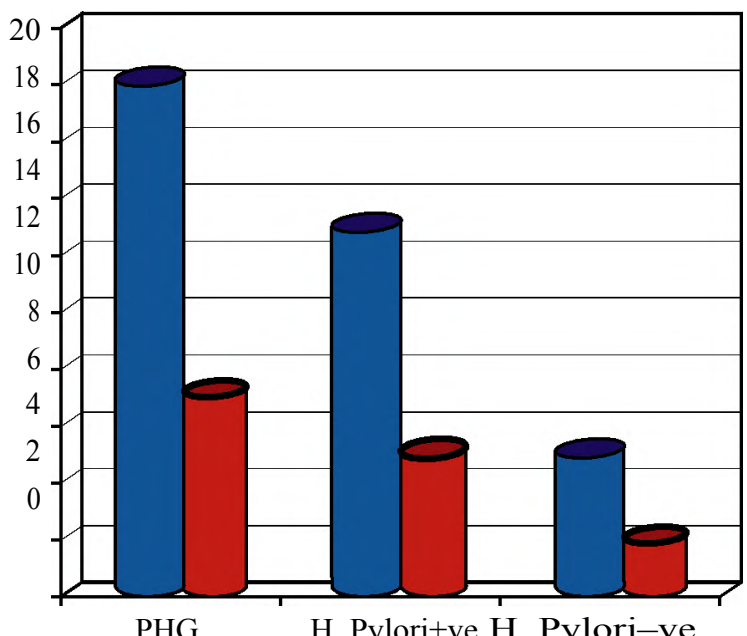

PHG

H. Pylori+ve H. Pylori-ve

Mild $\square$ Sever

Graph (1): Relation between H pylori infection and severity of PHG
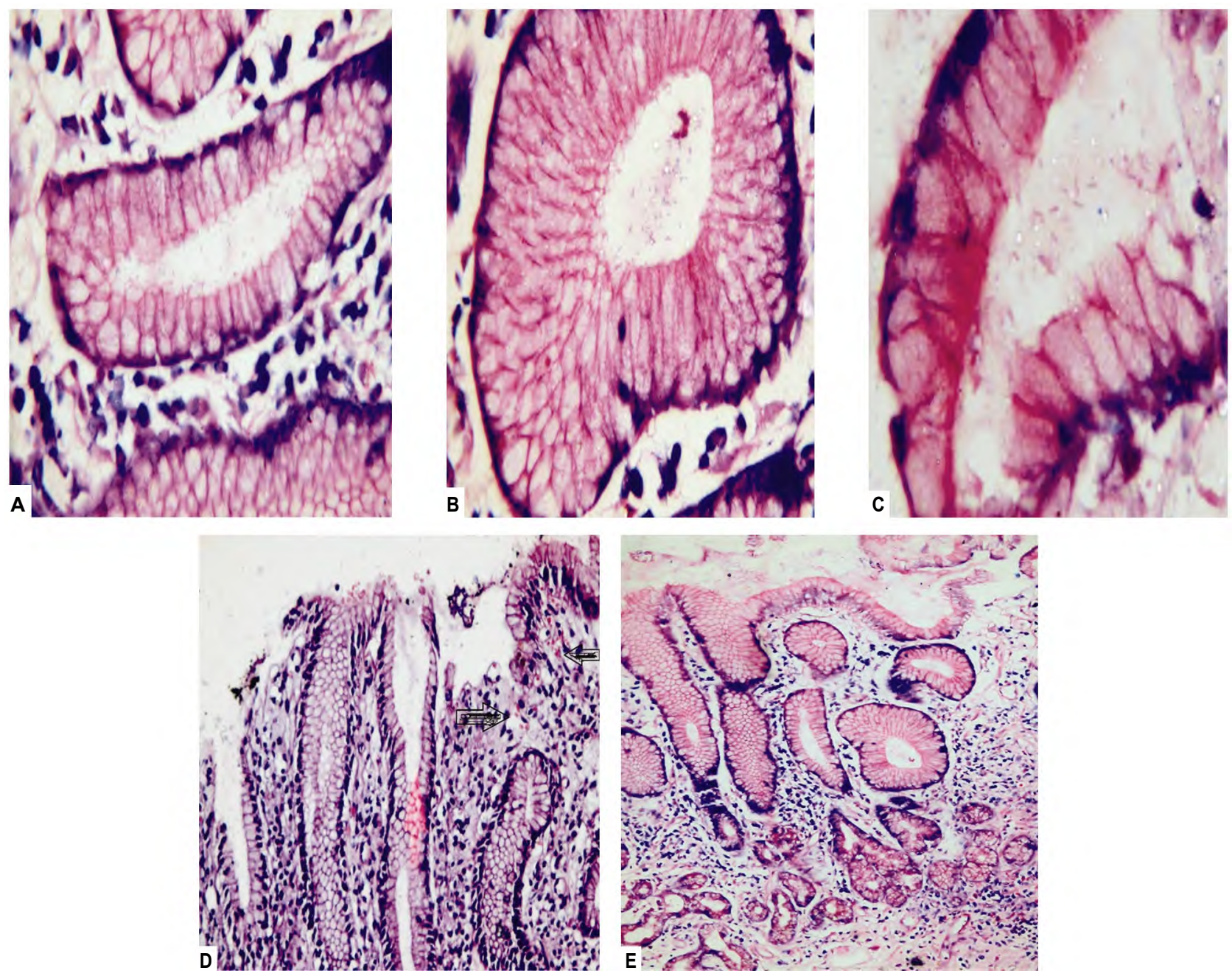

Fig. (1): H. pylori stained by Geimsa stain (A\&B\&C: X 300). D: Ectatic blood vessels at the gastric mucosa (black arrows) with H. pylori in the mucosa (red arrow) (X 100). E: Intestinal metaplasia and chronic inflammatory cell infiltration of the gastric mucosa in H. pylori infected cases (X 100). 

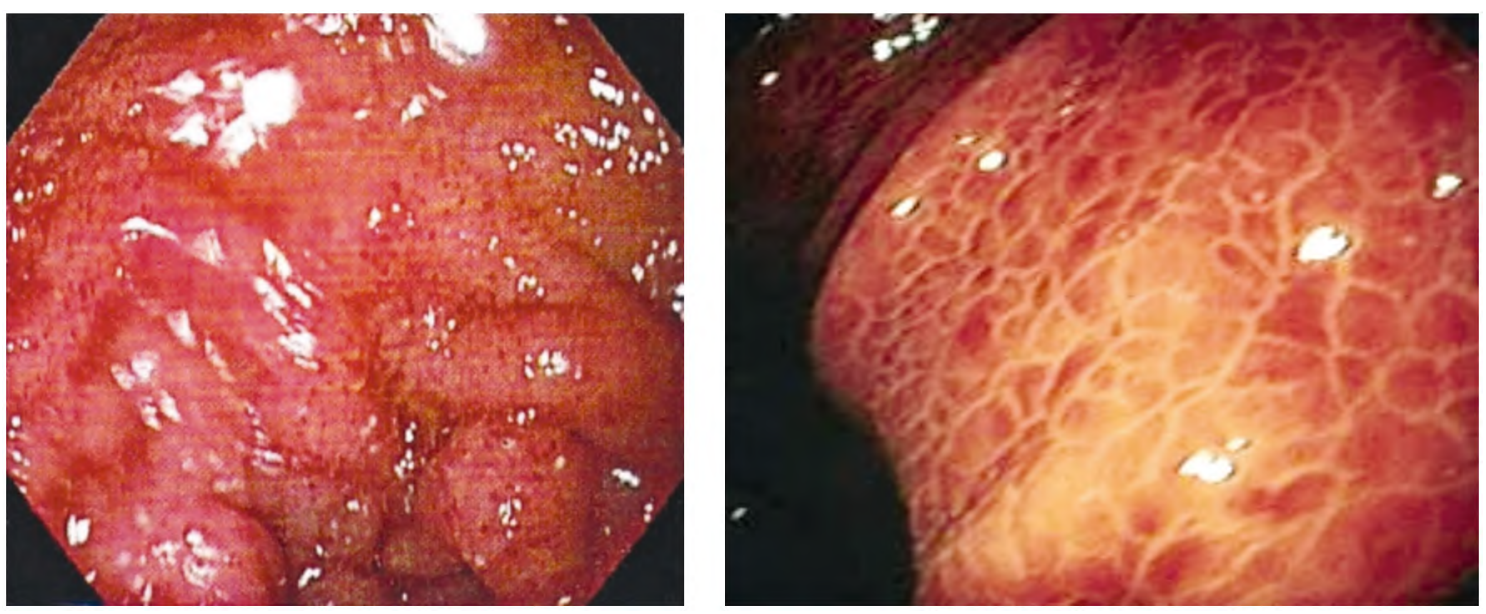

Fig. (2): Portal hypertensive gastropathy by endoscopy.

\section{Discussion}

The pathogenesis of PHG is not completely understood, however, evidence suggested that portal hypertension is a key factor, where elevated portal pressure can induce changes of local hemodynamics, thus causing congestion in the stomach. These changes may then activate cytokines and growth factors, such as tumor necrosis factor- a (TNF-a), which activate endothelial nitric oxide synthase and endothelin- 1 . Nitric oxide induces hyperdynamic circulation and peroxynitrite overproduction which, together with endothelin- 1 overproduction, may cause damage to gastric mucosa. When combined with the characteristics of impaired mucosal defense and healing, these factors may together produce PHG in patients with portal hypertension [12].

Colonization of the gastric mucosa by H. Pylori might have an indirect role in PHG as colonization is associated with inflammation. H. pylori virulence factors induce the production of pro-inflammatory cytokines such as TNF- a which affect mucosal inflammation [13].

Several investigators have evaluated the effect of $\mathrm{H}$. pylori on liver cirrhosis and PHG with controversial results. Some studies have shown a higher prevalence and a synergistic effect of $\mathrm{H}$. pylori on liver cirrhosis and PHG. However, most studies had not found any correlation between $\mathrm{H}$. pylori and PHG [14].

It found in a similar study that each of H. pylori and PHG independently increased inducible nitric oxide synthase (iNOS) in gastric mucosa of cirrhotic patients. However, its role in the development of PHG is still conflicting [15].
A meta-analysis included seven studies that assessed the prevalence of $\mathrm{H}$. pylori infection and endoscopic lesions associated with cirrhosis concluded that infection by $\mathrm{H}$. pylori was present in $60.7 \%$ of the patients with increased risk of developing peptic ulcer [16]

In the present study, we found that $\mathrm{H}$ pylori were detected histopathologically in $76 \%$ of the studied cases. Two recent studies found a prevalence of $62.1 \%$ [17] and 60\% [18] respectively, while a lower $\mathrm{H}$. pylori prevalence $(35.7 \%)$ was reported by Sathar et al [19]. This discrepancy could be attributed to the different tools of $\mathrm{H}$. pylori diagnosis.

We found that $\mathrm{H}$. Pylori infection in cirrhotic patients did not correlate with the presence or absence of PHG. A similar finding was documented by other researchers, after studying 60 cases of liver cirrhosis for $\mathrm{H}$. Pylori infection and its correlation with PHG [20].

Although we detected $\mathrm{H}$ pylori in 5 out of 7 cases of sever PHG, while $\mathrm{H}$ pylori was found in $13 / 18$ cases in mild PHG, there was no statistically significant correlation between $\mathrm{H}$ pylori infection and severity of PHG $(p>0.51)$.

Al Mofleh [14] found that there is no correlation between $\mathrm{H}$. pylori and etiology, stage of cirrhosis, presence and severity of PHG.

Batmanabane et al., [21] study found that 16/37 patients were positive for $\mathrm{H}$. pylori. $\mathrm{H}$. pylori status was $52 \%, 22 \%$, and $0 \%$ in patients with mild, moderate, and severe gastropathy respectively, indicating an inverse relationship of severity of PHG with H. pylori colonization. 
A retrospective study compared H. pylori seroprevalence between 70 cirrhotic with PHG (cases) and 70 matched cirrhotic without PHG (controls). The main results were that the prevalence of infection was higher in cases than controls $(44.3 \%$ vs. $27.1 \%, p=0.034)$, and the prevalence of severe PHG was higher in the $31 \mathrm{H}$. pylori infected compared to the 39 uninfected patients $(61.3 \%$ vs. $12.8 \%, p<0.001)$ [22].

A more recent study concluded that $\mathrm{H}$. pylori was detected in 33/60 (55\%) patients with liver cirrhosis and in 26 cases of liver cirrhosis with PHG compared to 7 cases of cirrhosis without PHG with statistically-significant differences, $p>0.0133$ [23]. Another recent study concluded that there is significant association between $\mathrm{H}$. pylori infection and PHG, but there is no significant correlation between $\mathrm{H}$. pylori infection and the severity of PHG or the severity of liver cirrhosis [24]

\section{Conclusions:}

Helicobacter pylori is highly prevalent in patients with liver cirrhosis with/without portal hypertensive gastropathy than in general population. Although there is no statistically significant relation between $\mathrm{H}$. pylori and the severity of PHG, routine eradication therapy using appropriate antibacterial drugs is beneficial in patients with portal hypertension with/without PHG. large prospective studies are recommended to investigate the relation between $\mathrm{H}$. pylori infection and gastropathy of hepatic etiology.

\section{References}

1- THULUVATH P.J. and YOO H.Y.: Portal hypertensive gastropath. The American Journal of Gastroenterology, 97: 2973-2978, 2002.

2- PRIMIGNANI M., CARPINELLI L., PREATONI P., BATTAGLIA G., CARTA A., PRADA A., CESTARI R., ANGELI P., GATTA A., ROSSI A., SPINZI G. and DE FRANCHIS R.: Natural history of portal hypertensive gastropathy in patients with liver cirrhosis. The New Italian Endoscopic Club for the study and treatment of esophageal varices (NIEC). Gastroenterology, 119: 181187,2000

3- FONTANA R.J., SANYAL A.J., GHANY M.G., BONKOVSKY H.L., MORGAN T.R., LITMAN H.J., REID A.E., LEE W.M. and NAISHADHAM D.: Development and progression of portal hypertensive gastropathy in patients with chronic hepatitis C. Am. J. Gastroenterol., 106: 884-893, 2011.

4- YOO H.W., EUSTACE J.A., VERMA S., ZHANG L., HARRIS M., KANTSEVOY S., LEE L.A., KALLO A.N., RAVICH W.J. and THULUVATH P.J.: Accuracy and reliability of the endoscopic classification of portal hypertensive gastropathy. Gastrointest. Endosc., 56 (5): 675$680,2002$.
5- THULUVATH P.J.: Management of upper gastrointestinal hemorrhage related to portal hypertension. In: Yamada T., Alpers D.H., Kalloo A.N., Kaplowitz N., Owyang C., Powell D.W., editors. Textbook of Gastroenterology. 5 th ed. Wiley Blackwell, 2897-3017, 2009.

6- PERINI R.F., CAMARA P.R. and FERRAZ J.G.: Pathogenesis of portal hypertensive gastropathy: Translating basic research into clinical practice. Nat Clin Pract Gastroenterol Hepatol., 6: 150-158, 2009.

7- MAKHIJA S., BURAK K. and BECK P.L.: Portal hypertensive gastropathy and gastric antral vascular ectasia. In: Helmy A, editor. Portal hypertension: Pathogenesis and management. New York: Nova Science Publishers Inc., 137-166, 2006.

8- KINJO N., KAWANAKA H., AKAHOSHI T., YAMAGUCHI S., YOSHIDA D., ANEGAWA G., KONISHI K., TOMIKAWA M., TANOUE K., TARNAWSKI A., HASHIZUME M. and MAEHARA Y.: Significance of ERK nitration in portal hypertensive gastropathy and its therapeutic implications. Am. J. Physiol. Gastrointest. Liver. Physiol., 295: G1016-G1024, 2008.

9- TAN S., WEI X., SONG M., TAO J., YANG Y. KHATOON S., LIU H., JIANG J. and WU B.: PUMA mediates ER stress induced apoptosis in portal hypertensive gastropathy. Cell Death Dis., 5: e1128, 2014.

10- HOOI J.K., LAI W.Y., NG W.K., SUEN M.M., UNDERWOOD F.E., TANYINGOH D., MALFERTHEINER P., GRAHAM D.Y., WONG V.W., WU J.C., CHAN F.K., SUNG J.J., GILAAD S.G., KAPLAN G.G. and NG S.C.: Global Prevalence of Helicobacter pylori Infection: Systematic Review and Meta-Analysis. Gastroenterology, 153 (2): 420-429, 2017.

11- PENG Y., QI X., DAI J., LI H. and GUO X.: Child-Pugh versus MELD scores for predicting the in-hospital mortality of acute upper gastrointestinal bleeding in liver cirrhosis. Int. J. Clin. Exp. Med., 8 (1): 751-757, 2015.

12- OHTA M., YAMAGUCHI S., GOTOH N. and TOMIKAWA M.: Pathogenesis of portal hypertensive gastropathy: A clinical and experimental review. Surgery, 9131 (1 Suppl): S165-70, 2002.

13- PATEL M.K., TROMBLY M.I. and KURT-JONES E.A.: Innate immune responses to Helicobacter pylori infection: An overview. Methods. Mol. Biol., 921: 205-7, 2012.

14- Al Mofleh I.A.: Does Helicobacter pylori affect portal hypertensive gastropathy? The Saudi J. of Gastroenterology, 13 (2): 95-97.

15- ARAFA U.A.1, FUJIWARA Y., HIGUCHI K., SHIBA M., UCHIDA T., WATANABE T., TOMINAGA K., OSHITANI N., MATSUMOTO T. and ARAKAWA T.: No additive effect between Helicobacter pylori infection and portal hypertensive gastropathy on inducible nitric oxide synthase expression in gastric mucosa of cirrhotic patients. Dig. Dis. Sci., 48 (1): 162-8, 2003.

16- VERGARA M., CALVET X. and ROQUÉ M.: Helicobacter pylori is a risk factor for peptic ulcer disease in cirrhotic patients. A meta-analysis. Eur. J. Gastroenterol. Hepatol., 14: 717-22, 2002.

17- ABBAS Z., YAKOOB J., USMAN M.W., SHAKIR T., HAMID S. and JAFRI W.: Effect of Helicobacter pylori and its virulence factors on Portal hypertensive gastropathy 
and interleukin (IL)-8, IL-10, and tumor necrosis factoralpha levels. Saudi. Gastroenterol., 20: 120-7, 2014.

18- SAFWAT E., HUSSEIN H.A. and HAKIM S.A.: Helicobacter pylori in Egyptian patients with HCV-related liver cirrhosis and portalHypertensive gastropathy: Prevalence and relation to disease severity. Life. Sc.i J., 12: 168-73, 2015.

19- SATHAR S.A., KUNNATHUPARAMBIL S.G., SREESH S., NARAYANAN P. and VINAYAKUMAR K.R.: Helicobacter pylori infection in patients with liver cirrhosis: prevalence and association with portal hypertensive gastropathy. Ann. Gastroenterol., 27: 48-52, 2014.

20- HAMMAD O.M., ABU-SEIF M.A., ASHOUR M. and HIFNAWY T.: Correlation of Portal Hypertensive Gastropathy with Helicobacter Pylori Infection, Liver Dysfunction, Hypersplenism and Esophageal Varices. Med. J. Cairo Univ., 77 (1): 597-601, 2009.

21- BATMANABANE V.1., KATE V. and ANANTHAKR-
ISHNAN N.: Prevalence of Helicobacter pylori in patients with portal hypertensive gastropathy-a study from south India. Med. Sci. Monit., 10 (4): 133-6, 2004.

22- ZULLO A., HASSAN C., RIDOLA L. and DEFRANCESCO V.: H. Pylori and portal hypertensive gastropathy: Any new information. Ann. Gastrenterol., 27 (1): 91, 2014.

23- PURI S and JAIN M.: Helicopacter pylori infection in patients with portal hypertensive gastropathy owing to liver cirrhosis-prevalence and relation with disease severity: A study from tertiary care center on North India. J. Of clinical and experimental. Hepatology, 7 (2): S62, 2017.

24- ABD-ALAZEIM KE, ABD EL-GAWAD M.S., METWALY AH, QASEM A.M. and ISMAIL M.M.: Prevalence of Helicobacter pylori infection in patients with portal hypertensive gastropathy owing to liver cirrhosis in Upper Egypt. Al-Azhar Assiut Medical. J., 14 (3): 109-114, 2016.

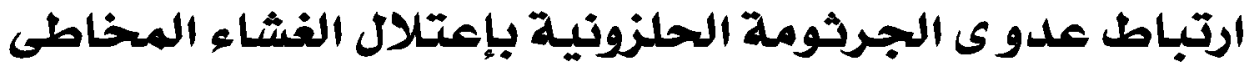

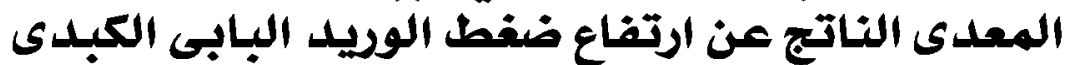

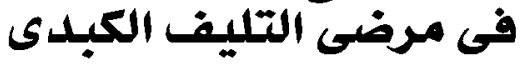

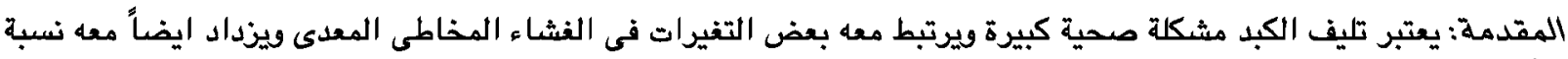

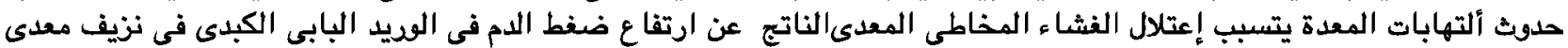

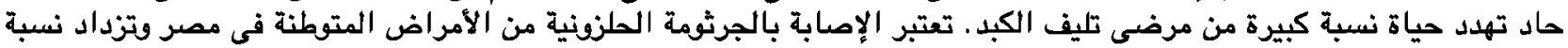

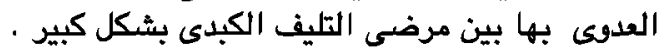

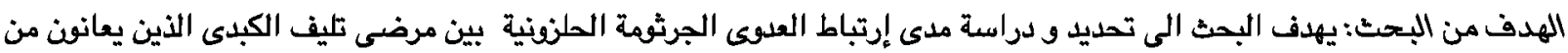

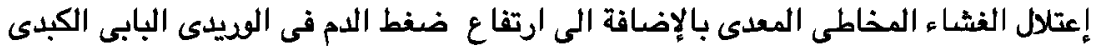

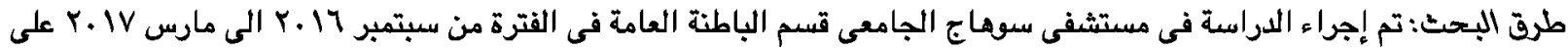

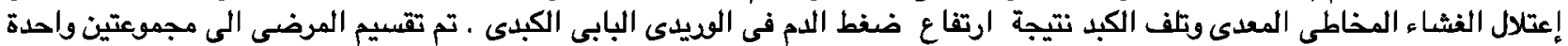

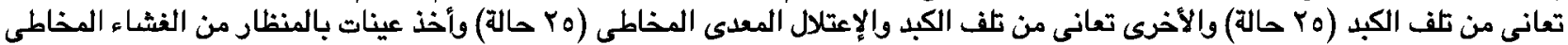

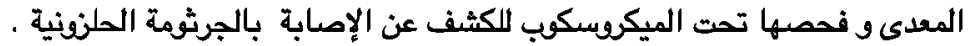

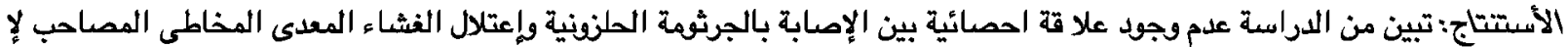

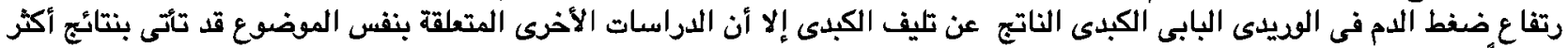
تصريداً في المستقبل. 